\title{
Investigating the Effects of Instructing Mothers Using BASNEF Model on Continuing Exclusive Breastfeeding of Late- Preterm Infants
}

\author{
Seyedeh Zahra Masoumi, ${ }^{1}$ Farideh Kazemi, ${ }^{2}$ and Sheler Ahmadi ${ }^{3,}{ }^{*}$ \\ ${ }^{1}$ Assistant Professor, Mother and Child Care Research Center, Department of Midwifery, School of Nursing and Midwifery, Hamadan University of Medical Sciences, Hamadan, \\ Iran \\ ${ }^{2} \mathrm{PhD}$ Candidate of Reproductive Health, Department of Midwifery and Reproductive Health, School of Nursing and Midwifery, Shahid Beheshti University of Medical \\ Sciences, Tehran, Iran \\ ${ }^{3}$ MSc of Consultation on Midwifery, Department of Midwifery, School of Nursing and Midwifery, Hamadan University of Medical Sciences, Hamadan, Iran \\ "Corresponding author: Sheler Ahmadi, MSc of Consultation on Midwifery, Department of Midwifery, School of Nursing and Midwifery, Hamadan University of Medical \\ Sciences, Hamadan, Iran. Tel: +98-9184570047, Fax: +98-8138380447. E-mail: ahmadi.sh64@gmail.com
}

Received 2016 September 20; Revised 2017 January 12; Accepted 2017 February 27.

\begin{abstract}
Background: According to the American academy of pediatrics, there is a high correlation between the length of exclusive breastfeeding and increased benefits of mothers and preterm infants. Evidence shows that breastfeeding support programs are effective in prolonging the lactation period, but the effect of these programs on the length of exclusive breastfeeding is not clear.

Objectives: The present study aimed at evaluating the effect of education on exclusive breastfeeding continuation in mothers with late- preterm infants.

Methods: In this randomized experimental study, 124 mothers of hospitalized late- preterm infants at Fatemiyeh hospital (Hamedan, Iran) were randomly assigned into 2 groups (intervention or control). The data collection instruments included a demographic questionnaire, BASNEF, and checklist for lactation visits, which were required to be completed by mothers in both groups. Moreover, weight gain in infants was measured by researchers before the treatment, and then once a month for a period of 2 months. For mothers in the intervention group, 5 sessions of breastfeeding education on BASNEF model was held during 5 consecutive days. Analyses were conducted using the SPSS 21.0; and a P value less than 0.05 was considered significant.

Results: Based on the results at the end of the first- and second- month follow-up, there were statistically significant differences between the intervention and control groups in lactation performance, knowledge, attitude, subjective norm, assessment of results, and enabling factors of the mothers $(\mathrm{P}<0.001)$. At the end of the first- and second- month follow-up, the difference between intervention and control mothers was statistically significant in exclusive breastfeeding continuation, in frequency of breastfeeding without the use of liquids, and feeding apart from breast milk and formula in day and night $(\mathrm{P}<0.001)$.

Conclusions: The results of this study revealed that breastfeeding instructional sessions were effective in encouraging mothers to continue exclusive breastfeeding the infants by breast milk; thus, it is suggested to encourage mothers to breastfeed based on the BASNEF model.
\end{abstract}

Keywords: Exclusive Breastfeeding, BASNEF Model, Preterm Infant

\section{Background}

Preterm birth occurs when an infant is born before the end of the 37th week of pregnancy (1). Infants born at the beginning of the 34th to the end of the 36th week of pregnancy, i.e., 239 to 259 days after the first day of a woman's last menstruation, are late-preterm infants (LPIs) (2). Preterm birth rate is $9.6 \%$ worldwide (3). In 2010, about half a million late-preterm infants of 34 to 37 weeks of gestation were born in the United States, that is, $71 \%$ of all preterm births (4). In Iran, preterm birth rate is reported to be $5.6 \%$ to $13.4 \%$ (5). Birth stress and physical underdevelopment in these infants place them at a greater risk of respiratory problems, hypoglycemia, sepsis, and jaundice, and most of them need intravenous or intraintestinal injections, or bottle feeding $(6,7)$. Moreover, insufficient breastfeeding exposes them to necrotizing enterocolitis, severe respiratory problems, digestive problems, asthma, obesity, and Type 2 diabetes $(8,9)$. These infants may look like term infants but are physically more vulnerable.

There are problems with LPI breastfeeding such as poor sucking ability and swallowing reflex, falling asleep, and fatigue before adequate feeding. Sucking rate in these infants may be high at first, but decreases during breastfeeding, which shows weakness in sucking; as a result, they receive a small amount of milk each time. To solve this problem, mothers need clinical instructions to use spoons and cups, gavage feeding, or finger feeding $(7,9,10)$. Even if these infants can start premature breastfeeding, many of them cause a decrease in milk production in their mothers because of their poor sucking or the fact that they cannot stimulate lactation by strong sucking. Therefore, many 
mothers would need breast pumps after giving birth in the hospital and later at home to maintain lactation for proper growth of their infants. This process must continue until the infant can suck enough milk (11). Breastfeeding is the best method of creating intimacy, connection, and skin-to-skin contact between mother and infant, instructing mothers how to feed their infants, and becoming aware of their consciousness (12). It has been shown that breastfeeding is related to decrease in a number of complications in infants such as necrotizing enterocolitis and sepsis (13). Breastfeeding instructions must start when the mother checks into the hospital with follow-ups to solve possible problems during the lactation period (14). According to the American academy of pediatrics, there is a high correlation between the length of exclusive breastfeeding and increased benefits of mothers and preterm infants (9).

Feeding infants only with their mother's milk, without any liquid or solid food except for vitamins, minerals, and medications during the first 6 months of birth is called exclusive breastfeeding (15). The importance of infant feeding is one of the policy priorities in most societies. The world health organization recommends that preterm infants be exclusively breastfed until the 6th month of birth (16). Based on reports from centers for disease control and prevention in the United States, the rate of exclusive breastfeeding of LPIs until the 6th month of birth was 73.1\% in 2009 (17). In Iran, despite the crucial efforts made by the ministry of health and medical education to promote breastfeeding (18), the rate of exclusive breastfeeding of infants until the 6th month of birth differs from 13\% to $77 \%$ (19-23). This shows mothers' need for support in breastfeeding after giving birth.

There is evidence that breastfeeding support programs are effective in prolonging the lactation period, but the effect of these programs on the length of exclusive breastfeeding is not clear (24). Based on a study, instructions on continuing exclusive breastfeeding in preterm infants can bring about a $26 \%$ increase in their weight (at least 500 g) and an increase in their height by the end of the first 2 months (25).

Studies show that the most effective theory-based instructional programs are rooted in models of behavior change in which choosing an appropriate model or theory of health education is the first step in the process of education planning, and skill in choosing the best theory makes an effective educational plan (26).

One of the models used in understanding behaviors is BASNEF (an acronym for beliefs, attitudes, subjective norms, and enabling factors), which is a comprehensive model and has been adopted to study behaviors and plans to alter them and define the factors affecting individuals' decision- making $(27,28)$. Sharifirad et al. found that breastfeeding education based on BASNEF model can improve breastfeeding behavior of mothers (29).

The importance of this model in LPI studies is that it takes into account personal beliefs, attitudes, and behaviors for planning and setting up behavior changes and consistency. In fact, it focuses on normative beliefs and subjective norms behind behavioral decisions for changing or continuing a certain behavior as well as enabling factors. As continuing exclusive breastfeeding of LPIs is a behavior instruction based on the BASNEF model, studying its effects on mothers' attitudes and performances in continuing exclusive breastfeeding can be introduced as a new instructional approach (30).

\section{Methods}

This was a randomized clinical trial, with the following inclusion criteria: literacy in reading and writing; single pregnancy; giving birth in 34th to 37th week of pregnancy; lack of addiction, systemic diseases, gestational diabetes, and preeclampsia in mothers; and lack of birth defects in infants. Among mothers attending breastfeeding instruction classes during pregnancy, those who did not want to take part in the study or attend the classes consistently, those mothers who consumed antidepressant or psychedelic drugs, and those with breast infections whose doctors prohibited them from breastfeeding were excluded from the study. Moreover, if infants died for any reason or could not be breastfed due to having a metabolic disease, respiratory distress, or hospital-acquired infection, their mothers were excluded from the study. In the study by Arzani et al. (31), the rate of breastfeeding in experimental and control groups was $60 \%$ and $40 \%$, respectively, $(\alpha=0.05)$, and the number of participants in each group was 62 , with the possibility of a $10 \%$ attrition rate. In line with their study and using permuted blocks of 4 and a random numbers table, in this study, participating mothers were randomly assigned into an experimental and control group. Sampling was performed at the neonatal care unit of Fatemiyeh hospital in Hamedan for 8 months from October 2014 to June 2015. Data collection instruments were a researcher-made demographic questionnaire, the BASNEF questionnaire (an example of the questions in this questionnaire is listed in Box 1), a breastfeeding observation checklist, and pediatric scales. The demographic questionnaire included 28 items, which included personal information (8), history of pregnancies (7), continuing exclusive breastfeeding (10), and present pregnancy (3). Breastfeeding observation checklist consisted of 17 questions about breastfeeding performance of mothers. For instructing based on the BASNEF model, the questionnaires used by Sharifirad (29) (components of attitude, enabling factors, 
and subjective norms) and Keramat (32) (components of awareness, behavioral intention, and evaluation of results) were used. The final BASNEF model included 20 threeoption items on breastfeeding awareness, scored on a 0 to 20 scale (each correct answer received 1 point, and each wrong answer or unanswered item received 0 point); 10 five-option items on attitude, scored on a 0 to 40 scale (each item scored on a 0-4 Likert scale, 4 being the highest); 8 items on subjective norms, scored on an 8 to 20 scale (each item scored on a 1-3 Likert scale); 7 four-option items on enabling factors, scored on a 0 to 7 scale (each correct answer received 1 , and each wrong answer or unanswered item received 0 point); 3 multiple-choice items on behavioral intention, scored on a 0 to 3 scale (each correct answer received one, and each wrong answer or unanswered item received 0 point); and 5 multiple-choice items on evaluation of results, scored on a 0 to 5 scale (each correct answer received 1, and each wrong answer or unanswered item received 0 point). For an easy comparison, the obtained scores were later converted into percentages.

To check the reliability of the checklist and questionnaires used in this study, content reliability was measured. Moreover, for the questionnaires, Cronbach's alpha was measured based on 20 participants. The same procedure was used for breastfeeding observation checklist $(\alpha=$ 0.92 ), and for BASNEF questionnaire in questions on awareness ( $\alpha=0.72$ ), attitude $(\alpha=0.70)$, subjective norms ( $\alpha=$ 0.9 ), enabling factors $(\alpha=0.83$ ), evaluation of results ( $\alpha=$ 0.79 ), and behavioral intention ( $\alpha=0.86)$, and for the demographic questionnaire in questions on continuing exclusive breastfeeding $(\alpha=0.81$ ). To measure the reliability of the pediatric scales, weight was checked against a standard 500-g weight before weighing infants.

The aim of the study was explained to the participating mothers, and then written consent was obtained. Afterwards, mothers in the both groups completed the researcher-made demographic questionnaire, the BASNEF questionnaire, and the breastfeeding observation checklist, face-to-face with the researcher at the hospital once before the intervention, and then every month until 2 months after giving birth. To educate mothers to continue exclusive breastfeeding LPIs, the researcher held five 30minute breastfeeding instruction sessions for mothers of the experimental group during the time their infants were at the hospital. Instructions were in the form of theoretical and practical face-to-face and personal sessions (with mock-ups, pamphlets, and incentive packages) according to a daily goals table. The sessions were held in consecutive days, starting when the oral feeding of infants began as approved by a medical specialist until infants were discharged from the hospital. In the case of infants who were discharged earlier, the rest of the sessions were held at the hospital after appointments were made with parents and the hospital staff.

The educational content consisted of definition of natural and artificial feeding and their pros and cons, definition of exclusive breastfeeding, importance of breastfeeding in the first hours of giving birth, causes of postpartum breast infections, methods of storing breast milk, wrong reasons for starting artificial feeding, healthy breastfeeding diet, and correct techniques of breastfeeding preterm infants and their correct application by mothers. The control group received only routine postpartum instructions from the neonatal care unit personnel. Furthermore, infants from the both groups were weighed while wearing only light clothing by standard pediatric scales before the intervention and, and then, once a month for 2 months.

In the last instructional session, an incentive package (including a book on feeding a preterm infant and an instructional $\mathrm{CD}$ ) and instructional pamphlet were given to mothers in the experimental group. In keeping with the codes of ethics, mothers in the control group also received the package and pamphlet after the 2-month follow-up.

Then, the data collected from the experimental and control group before and after the intervention were analyzed at the significance level of $\mathrm{P}<0.005$ using SPSSv.21, and descriptive statistics such as number, percentage, mean, and SD and inferential statistics such as chi-squared test, Mann-Whitney U test, and t test (paired and independent samples).

\section{Results}

The mean age of mothers in the experimental and control group was $27.13 \pm 0.53$ and $27.19 \pm 0.60$ years, respectively. More than $80 \%$ of the mothers had a monthly salary of less than 10,000,000 Rials. Moreover, most of them $(76.60 \%)$ had a history of previous pregnancy; in both groups, $69.4 \%$ were delivered by Cesarean section and $30.6 \%$ by normal vaginal delivery method. Over $14 \%$ had a history of preterm birth. Over three-fourth of mothers in the both groups had exclusively breastfed their previous children for 6 months. Mean pregnancy age was $34.31 \pm$ 0.46 for both groups at the time of giving birth. In each group, there were 33 (53.2\%) male and 29 (46.8\%) female infants. There was no statistically significant difference between the 2 groups in the above criteria.

The repeated measure ANOVA was used to evaluate the mean scores of the BASNEF components (except for behavioral intention) in the 2-month follow-up after the intervention. According to the results, the 2 groups had different means of 3 measurements before and after the intervention $(\mathrm{P}<0.001)$. To compare the means of the 2 groups 
Box 1. Questions about Attitude to Continuing Exclusive Breastfeeding of Late-Preterm Infants

\begin{tabular}{|c|c|c|c|c|c|}
\hline Questions & Strongly Agree & Agree & Neither agree nor disagree & Disagree & Strongly Disagree \\
\hline \multicolumn{6}{|l|}{$\begin{array}{l}\text { 1- Breastfeeding in premature infants is more difficult than } \\
\text { in term infants. }\end{array}$} \\
\hline \multicolumn{6}{|l|}{$\begin{array}{l}\text { 2- Breastfeeding can guarantee my health and the health of } \\
\text { my premature infants. }\end{array}$} \\
\hline \multicolumn{6}{|l|}{$\begin{array}{l}\text { 3- It is better to use the formula for premature infants, if the } \\
\text { economic situation is good. }\end{array}$} \\
\hline \multicolumn{6}{|l|}{$\begin{array}{l}\text { 4- Breastfeeding in preterm babies no different after a } \\
\text { vaginal delivery or cesarean section. }\end{array}$} \\
\hline \multicolumn{6}{|l|}{$\begin{array}{l}\text { 5- Formula is a } 100 \% \text { ideal method for feeding premature } \\
\text { infants. }\end{array}$} \\
\hline \multicolumn{6}{|l|}{$\begin{array}{l}6 \text { - I think I am not able to breastfeeding because of a sense of } \\
\text { weakness and morbidity in my premature infants. }\end{array}$} \\
\hline \multicolumn{6}{|l|}{$\begin{array}{l}\text { 7- Except for Formula, there is no alternative and indirectly } \\
\text { method for feeding premature infants. }\end{array}$} \\
\hline \multicolumn{6}{|l|}{$\begin{array}{l}\text { 8- The growth of premature infant is like matures and does } \\
\text { not require special care. }\end{array}$} \\
\hline \multicolumn{6}{|l|}{$\begin{array}{l}\text { 9- I prefer Formula on the breast feeding, due to fear of } \\
\text { infecting the premature infant to infections and diseases. }\end{array}$} \\
\hline $\begin{array}{l}\text { 10- If you have breastfeeding, the risk of postpartum } \\
\text { hemorrhage and maternal anemia is less. }\end{array}$ & & & & & \\
\hline
\end{tabular}

at a certain time, independent sample t test was used. Results revealed that the 2 groups had no significant difference in any of the model's components prior to the intervention; however, there was a significant difference between the groups after the intervention in the first and second month of follow-up $(\mathrm{P}<0.001)$. In each group, to compare the components' means before the intervention with those obtained during each follow- up month, paired sample t tests were performed. Results demonstrated no significant differences in the control group in the components' means before the intervention and 1 month after the intervention or before the intervention and 2 months after the intervention. However, in the experimental group, significant differences were observed in both the followup months and for all the components $(\mathrm{P}<0.001)$ (Table 1). Because the behavioral intention questions had special types of choices, paired sample t test or repeated measure ANOVA were not performed for them. Based on the results of the independent sample t test, in Question 1 of the behavioral intention component (What kind of feeding will you select?), there was no meaningful difference between the groups before the intervention and 1 month after the intervention, but this difference was significant in the second month. In Questions 2 and 3 of the same component (Do you plan to continue exclusive breastfeeding of your infant for the first 6 months of birth?; and do you plan to continue breastfeeding for 2 years?), there was no meaningful difference between the groups before the interven- tion, but this difference was significant in the first and second month of follow-up $(\mathrm{P}<0.001)$.

Moreover, no significant difference was observed between the groups in continuing exclusive breastfeeding prior to the intervention; however, according to the results of the Mann-Whitney U test, the mean number of times of breastfeeding was significantly more in the experimental than in the control group during the first and second months after the intervention $(\mathrm{P}<0.001)$. Moreover, based on the results of the chi-squared test, there was a significant difference between the 2 groups in feeding with other fluids, artificial feeding, and formula feeding during the 2 months of the follow- up $(\mathrm{P}<0.001)$ (Table 2$)$.

The repeated measure ANOVA was used to compare the breastfeeding performances of mothers (Table 3 ) and weights of infants (Table 4 ) during the 2 months of followup. The results revealed that the mean breastfeeding performance $(\mathrm{P}<0.001, \mathrm{~F}=19.058)$ and weights of infants $(\mathrm{P}$ $<0.001, \mathrm{~F}=22.84$ ) (once before and 2 times after the intervention) showed a significant difference in the 3 measurements. Independent samples t test demonstrated no significant difference between the abovementioned variables in the 2 groups prior to the intervention, while the difference became meaningful during the first and second months of follow-up $(\mathrm{P}<0.001)$. 
Table 1. Comparing Mean Scores of the BASNEF Model Components in the Experimental and Control Group in Follow-up Months ${ }^{\mathrm{a}}$

\begin{tabular}{|c|c|c|c|c|c|}
\hline RM Between Groups & $\begin{array}{l}\text { Second Month After } \\
\text { Training }\end{array}$ & $\begin{array}{l}\text { The First Month After } \\
\text { Training }\end{array}$ & Before Training & Group & Structures BASNEF \\
\hline \multirow{2}{*}{$F=16.30, P<0.001$} & $63.47 \pm 12.03$ & $67.1 \pm 12.1$ & $47.42 \pm 12.43$ & Training & \multirow{2}{*}{ Knowledge } \\
\hline & $39.9 \pm 9.7$ & $44.4 \pm 10.9$ & $47.3 \pm 9.7$ & Control & \\
\hline \multirow{2}{*}{$F=5.60, P<0.001$} & $43.2 \pm 2.4$ & $40.1 \pm 2.4$ & $34.1 \pm 4.55$ & Training & \multirow{2}{*}{ Attitude } \\
\hline & $33.2 \pm 4.5$ & $33.3 \pm 4.2$ & $33.2 \pm 4.5$ & Control & \\
\hline \multirow{2}{*}{$F=39.324, P<0.001$} & $13.82 \pm 1.62$ & $13.67 \pm 1.30$ & $13.65 \pm 1.79$ & Training & \multirow{2}{*}{ Subjective norms } \\
\hline & $12.25 \pm 0.83$ & $12.26 \pm 0.75$ & $13.62 \pm 1.37$ & Control & \\
\hline \multirow{2}{*}{$F=324.14, P<0.001$} & $11.29 \pm 0.76$ & $10.4 \pm 1.12$ & $8.99 \pm 1.51$ & Training & \multirow{2}{*}{ Enabling factors } \\
\hline & $7.43 \pm 1.02$ & $7.43 \pm 1.02$ & $8.04 \pm 1.69$ & Control & \\
\hline$F=39.425, P<0.001$ & $3.17 \pm 1$ & $3.38 \pm 1.10$ & $2.04 \pm 1.19$ & Training & Outcome evaluation \\
\hline
\end{tabular}

${ }^{\mathrm{a}}$ Values are expressed as mean $\pm \mathrm{SD}$.

Table 2. Comparing Absolute and Relative Frequencies and Means of the Questions on Continuing Exclusive Breastfeeding in the Experimental and Control Group ${ }^{\text {a }}$

\begin{tabular}{|c|c|c|c|c|}
\hline Statistic (P Value) & Control Group & Training Group & & Questions \\
\hline $\mathrm{P}=0.642^{\mathrm{b}}, \mathrm{x}^{2}=42.10$ & $60(96.8)$ & $54(87.1)$ & Before Training & \multirow{3}{*}{ Do not use liquids other than breast milk during the day } \\
\hline$P<0.001, x^{2}=134.15$ & $41(66.0)$ & $58(93.5)$ & The first month after Training & \\
\hline $\mathrm{P}<0.001, \mathrm{x}^{2}=134.15$ & $41(66.1)$ & $58(93.5)$ & Second month after Training & \\
\hline$P=0.437^{b}, x^{2}=34.23$ & $33(53.2)$ & $37(59.7)$ & Before Training & \multirow{3}{*}{ Do not use any food other than breast milk during the day } \\
\hline$P<0.001, x^{2}=58.78$ & $12(19.35)$ & $54(87.1)$ & The first month after Training & \\
\hline $\mathrm{P}<0.001, \mathrm{x}^{2}=58.77$ & $11(17.7)$ & $51(82.20)$ & Second month after Training & \\
\hline $\mathrm{P}=0.211^{\mathrm{c}}, \mathrm{t}=0.49$ & $32(51.6)$ & $24(38.7)$ & Before Training & \multirow{3}{*}{ Baby formula feeding } \\
\hline $\mathrm{P}<0.001, \mathrm{t}=3.64$ & $51(82.3)$ & $7(11.3)$ & The first month after Training & \\
\hline $\mathrm{P}<0.001, \mathrm{t}=4.26$ & $52(83.9)$ & $11(17.7)$ & Second month after Training & \\
\hline$P=0.60^{d}, u=1827.5$ & $2.44 \pm 0.861$ & $2.52 \pm 0.784$ & Before Training & \multirow{3}{*}{ Frequency of breastfeeding per day } \\
\hline $\mathrm{P}<0.001, \mathrm{u}=\mathbf{8 6 8 . 5}$ & $4.03 \pm 1.187$ & $5 \pm 0.675$ & The first month after Training & \\
\hline $\mathrm{P}<0.001, \mathrm{u}=629$ & $3.95 \pm 1.299$ & $5.33 \pm 0.711$ & Second month after Training & \\
\hline$P=0.75^{d} u=1864.5$ & $2.42 \pm 0.789$ & $2.39 \pm 0.875$ & Before Training & \multirow{3}{*}{ How often to replace baby diaper per day } \\
\hline$P=0.97, u=1793$ & $4.03 \pm 0.652$ & $4.05 \pm 0.347$ & The first month after Training & \\
\hline$P=0.01, u=1392$ & $4.35 \pm 0.704$ & $4.17 \pm 0.381$ & Second month after Training & \\
\hline
\end{tabular}

${ }^{\mathrm{a}}$ Values are expressed as No. (\%) or mean $\pm \mathrm{SD}$.

${ }^{\mathrm{b}}$ Chi-square test.

'Independent t-tests.

${ }^{\mathrm{d}}$ Mann-Whitney U test.

\section{Discussion}

Breast milk includes the best nutrients for the growth of late-preterm infants, and thus exclusive breastfeeding can benefit such infants in many ways. Accordingly, studies confirm that breastfed infants are less likely to develop infections and fever, or lose energy and nutrients by bowel movements $(33,34)$. According to this study, exclusive breastfeeding continued more in the experimental than in the control group. Aidam et al. (35) found that breastfeeding instructions can increase the length of exclusive breastfeeding. In addition, Thakur et al. (25) proved that with 2 months of instruction, the length of exclusive breastfeeding can be increased and the risk of respiratory 
Table 3. Comparing Mean Breastfeeding Performances in the Experimental and Control Group ${ }^{\mathrm{a}}$

\begin{tabular}{l|c|c|l|l}
\hline Variable & Group & Before Training & The First Month After Training & Second Month After Training \\
\hline \multirow{2}{*}{ Breastfeeding performances } & Training & $5.61 \pm 1.86$ & $7.52 \pm 2.21$ & $8.01 \pm 1.88$ \\
\cline { 2 - 5 } & Control & $5.85 \pm 1.84$ & $5.90 \pm 1.96$ & $5.84 \pm 1.84$ \\
\hline The results of independent t-test & & $\mathrm{P}=0.07, \mathrm{t}=-2.80$ & $\mathrm{P}<0.001, \mathrm{t}=4.22$ & $\mathrm{P}<0.001, \mathrm{t}=6.33$ \\
\hline
\end{tabular}

${ }^{\mathrm{a}}$ Values are expressed as mean $\pm \mathrm{SD}$.

Table 4. Comparing Mean Weights of Infants in the Experimental and Control Group ${ }^{\mathrm{a}}$

\begin{tabular}{l|c|c|l|l}
\hline Variable & Group & Before Training & The First Month After Training & Second Month After Training \\
\hline \multirow{2}{*}{ Weights of infants, $g$} & Training & $2112.26 \pm 439.21$ & $2818.62 \pm 588.54$ & $3844.83 \pm 642.68$ \\
\cline { 2 - 5 } & Control & $2126.29 \pm 453.96$ & $2422.58 \pm 607.17$ & $3296.45 \pm 684.24$ \\
\hline The results of independent t-test & & $\mathrm{P}=0.86, \mathrm{t}=-0.17$ & $\mathrm{P}<0.001, \mathrm{t}=3.62$ & $\mathrm{P}<0.001, \mathrm{t}=4.5$ \\
\hline
\end{tabular}

${ }^{\mathrm{a}}$ Values are expressed as mean $\pm \mathrm{SD}$

diseases, diarrhea, and infections in low weight infants can be decreased. Results of the present study confirm these findings.

According to the present study, the mean breastfeeding performance of mothers in the experimental group increased in both the first and second month of follow up, while in the control group it increased only in the first month.

Britton et al. (36) showed that breastfeeding instructions by health experts such as nurses and midwives bring about a 33\% and 10\% decrease in discontinuation of exclusive breastfeeding, respectively, 4 to 6 weeks and 6 months after giving birth. Based on the results of several studies, exclusive breastfeeding increases when there is support for breastfeeding (37-41). Breastfeeding instructions can improve the results of breastfeeding, e.g., by help solve breastfeeding problems (42).

Furthermore, based on the results obtained in this study, only 11 (17.7\%) mothers in the experimental group had "very good" or "good" levels of awareness about breastfeeding LPIs; this number increased to 46 (74.8\%) and 42 (68.4\%) by the end of the first and second month. On the other hand, only 9 (14.5\%) control group mothers had the same levels of awareness prior to intervention, and this number, respectively, decreased to 5 (8.1\%) and 2 (3.2\%) by the end of the first and second months. Khoury et al. (43) found that higher level of mothers' awareness and knowledge of breastfeeding and its benefits leads to further continuation of exclusive breastfeeding. In addition, Scott et al. (44) revealed a direct correlation between raising mothers' awareness of breastfeeding and continuation of exclusive breastfeeding. Results of the present study are in line with these findings.

The study by Keramat et al. (32) demonstrated that breastfeeding instructions not only increase mothers' awareness and performance of breastfeeding, but also improve their attitudes towards it. Such a conclusion has been confirmed by other studies $(29,45)$. The present study also shows that programs or instructions based on the BASNEF model can improve mothers' attitudes towards breastfeeding.

Moreover, the results in this study indicated a statistically significant difference between subjective norms of the experimental group mothers before and after the intervention. Instructions alone do not have a large impact on the changing patterns and norms of correct breastfeeding behavior; to change these norms, we need extensive education programs, which also include the mother's relatives such as spouse, mother, mother-in-law, and friends (29). Therefore, to deal with this limitation, in the present study, we held one instructional session for mothers on a factor of subjective norm component, which received the highest mean, and thus was most influential on mothers' decision-making.

Kordi et al. (46) demonstrated that midwives' supportive care of mothers has a positive effect on continuing exclusive breastfeeding. In addition, Brown et al. (47) showed that accepting breastfeeding as a norm in the society and providing social support for mothers are influential in continuing breastfeeding. According to the studies by Bertini, the most important factors in starting and continuing breastfeeding are support from spouse, acceptance of breastfeeding behavior as a social norm, support from friends, attending counseling sessions, and postpar- 
tum support, and pursuit. Results of the present study are in accordance with these findings (48).

Evidence suggests that there is a high correlation between the number of breastfeeding instruction sessions held for mothers and the continuation of exclusive breastfeeding (49). In most studies, mothers complained that health workers were not available when they had a problem with breastfeeding (50), and considered this problem as a setback in continuing exclusive breastfeeding (51). In the present study, the presence of social support as one of the enablers in the BASNEF model was studied by holding instructional classes for the experimental group mothers and making the researcher available as a trained person, who could solve mothers' problems; and the results revealed that the mean scores of the enablers in the experimental group mothers increased in both the first- and second- month of follow-up, while these mean scores decreased for the control group mothers in the first- and second- month of follow-up.

According to the results of the present study, holding instructional classes based on the BASNEF model helps improve the continuation of exclusive breastfeeding, breastfeeding performance, and weight gain in late preterm infants during the first 2 months of birth. It also improves awareness, attitude, evaluation of results, and behavioral intentions in the mothers to continue exclusive breastfeeding.

\subsection{Ethical Approval}

All procedures performed in studies involving human participants were in accordance with the ethical standards of the institutional and/or national research committee and with the 1964 Helsinki declaration and its later amendments or comparable ethical standards.

\section{Acknowledgments}

This study was based on an M.A. thesis in midwifery counseling and accepted by the center for research and technology development, Hamedan University of Medical Sciences (Registration number: 9310235220, registration number IRCT: IRCT2014111013405N6). Researchers express their deep gratitude to the personnel of Fatemiyeh hospital in Hamedan and the mothers who cooperated with us in conducting this research.

\section{Footnotes}

Authors' Contribution: Study concept and design, Seyedeh Zahra Masoumi, Sheler Ahmadi; acquisition of data, Seyedeh Zahra Masoumi, Sheler Ahmadi; analysis and interpretation of data, Seyedeh Zahra Masoumi, Farideh Kazemi, Sheler Ahmadi; drafting of the manuscript, Seyedeh Zahra Masoumi, Farideh Kazemi, Sheler Ahmadi; critical revision of the manuscript for important intellectual content, Seyedeh Zahra Masoumi; statistical analysis, Seyedeh Zahra Masoumi, Sheler Ahmadi; study supervision, Seyedeh Zahra Masoumi.

Implication for Health Policymak-
ers/Practice/Research/Medical Education: Educating mothers based on BASNEF model is effective in encouraging them to exclusively breastfeed their infants.

\section{Funding/Support: None.}

\section{References}

1. Tenhaaf JJ. Critical review: The effects of oral stimulation on feeding behaviours in preterm infants. 2008

2. Haiden N. Ernährung des Frühgeborenen. Monatsschr Kinderheilkd. 2014;162(9):785-91. doi: 10.1007/s00112-014-3107-8.

3. Beck S, Wojdyla D, Say L, Betran AP, Merialdi M, Requejo JH, et al. The worldwide incidence of preterm birth: a systematic review of maternal mortality and morbidity. Bull World Health Organ. 2010;88(1):31-8. doi: 10.2471/BLT.08.062554. [PubMed: 20428351].

4. Martin JA, Hamilton BE, Sutton PD, Ventura SJ, Mathews TJ, Osterman MJ. Births: final data for 2008. Natl Vital Stat Rep. 2010;59(1):1. [PubMed: 22145497] 3-71.

5. Medoff Cooper B, Holditch-Davis D, Verklan MT, Fraser-Askin D, Lamp J, Santa-Donato A, et al. Newborn clinical outcomes of the AWHONN late preterm infant research-based practice project. J Obstet Gynecol Neonatal Nurs. 2012;41(6):774-85. doi: 10.1111/j.1552-6909.2012.01401.x. [PubMed: 22861492].

6. Kamali Fard M, Alizadeh R, Sehati Shafaei F, Gojazadeh M. The effect of lifestyle on the rate of preterm birth [In Persian].J Ardabil Univ Med Sci. 2010;10(1):55-63.

7. Walker M. Breastfeeding the late preterm infant. J Obstet Gynecol Neonatal Nurs. 2008;37(6):692-701. doi: 10.1111/j.15526909.2008.00293.x. [PubMed: 19012718].

8. Bakewell-Sachs S, Medoff-Cooper B, Escobar GJ, Silber JH, Lorch SA. Infant functional status: the timing of physiologic maturation of premature infants. Pediatrics. 2009;123(5):e878-86. doi: 10.1542/peds.2008-2568. [PubMed: 19403481].

9. Section on B. Breastfeeding and the use of human milk. Pediatrics. 2012;129(3):e827-41. doi: 10.1542/peds.2011-3552. [PubMed: 22371471].

10. Nyqvist KH, Haggkvist AP, Hansen MN, Kylberg E, Frandsen AL, Maastrup R, et al. Expansion of the ten steps to successful breastfeeding into neonatal intensive care: expert group recommendations for three guiding principles. J Hum Lact. 2012;28(3):289-96. doi: 10.1177/0890334412441862. [PubMed: 22674967].

11. Lucas R, Gupton S, Holditch-Davis D, Brandon D. A case study of a late preterm infant's transition to full at-breast feedings at 4 months of age. J Hum Lact. 2014;30(1):28-30. doi: 10.1177/0890334413495973. [PubMed: 23860267].

12. Meier P, Patel AL, Wright K, Engstrom JL. Management of breastfeeding during and after the maternity hospitalization for late preterm infants. Clin Perinatol. 2013;40(4):689-705. doi: 10.1016/j.clp.2013.07.014. [PubMed: 24182956].

13. Schanler RJ. Outcomes of human milk-fed premature infants. Semin Perinatol. 2011;35(1):29-33. doi: 10.1053/j.semperi.2010.10.005. [PubMed: 21255704].

14. Walker M. Breastfeeding the late preterm infant: Improving care and outcomes. Hale Pub.; 2009. 
15. Kliegman RM, Stanton BF, Schor NF. Nelson' textbook of pediatrics. 19th ed. Philadelphia: Saunders Co; 2011. pp. 555-65.

16. Singh D, Devi N, Raman Ts R. Exclusive Breast Feeding in Low Birth Weight Babies. Med J Armed Forces India. 2009;65(3):208-12. doi: 10.1016/S0377-1237(09)80004-X. [PubMed: 27408247].

17. Centers for Disease Control and Prevention . Division of nutrition, physical activity, and obesity. 2015. US National Immunization Survey (NIS). 2012.

18. The ministry of health $M$, Education M. Perspective of children nutrition in states. 1th ed. Tehran: Ministry health of nutrition department; 1998.

19. Almasi H, Saberi H, Moravveji SA. The pattern of exclusive breast feeding in neonates under healthcares in health centers of Kashan city during 2006. J Kashan Univ Med Sci. 2010;14(2):163-8.

20. EslamiZ. The relationship between types of delivery on breastfeeding success. J Pediatr Iran. 2009;18(1):47-52.

21. Mohammad Beygi A, Mohammad Salehy N, Bayati A. The pattern of exclusive breast feeding in referred neonatal to health centers of Arak [In Persian].J Guilan Univ Med Sci. 2009;18(70):17-25.

22. Olang B, Farivar K, Heidarzadeh A, Strandvik B, Yngve A. Breastfeeding in Iran: prevalence, duration and current recommendations. Int Breastfeed J. 2009;4:8. doi: 10.1186/1746-4358-4-8. [PubMed: 19656361].

23. Vafaee A, Khabazkhoo M, Moradi A, Najafpoor AA. Prevalence of Exclusive Breastfeeding During the First Six Months of Life and its Determinant Factors on the Referring Children to the Health Centers in Mashhad, Northeast of Iran-2007. J Appl Sci. 2010;10(4):343-8. doi: 10.3923/jas.2010.343.348.

24. Centers for Disease C. Breastfeeding trends and updated national health objectives for exclusive breastfeeding-United States, birth years 2000-2004. MMWR Morb Mortal Wkly Rep. 2007;56(30):760-3. [PubMed: 17673896].

25. Thakur SK, Roy SK, Paul K, Khanam M, Khatun W, Sarker D. Effect of nutrition education on exclusive breastfeeding for nutritional outcome of low birth weight babies. Eur JClin Nutr. 2012;66(3):376-81. doi: 10.1038/ejcn.2011.182. [PubMed: 22085870].

26. Sha-Mohammadi Z, Jalilian F, Mirzaei-Alavijeh M, Mahboubi M, ZinatMotlagh F, Karami-Matin B, et al. Intention and Behavioral Stages in Pap Testing: A Cross-Sectional Study among Kermanshah Women's, the west of Iran. J Biol Today's World. 2014;3(1):11-4

27. Kakaei H, Mirzaei Alavijeh M, Mahboubi M, Maghsodi Moghadam R, Zinat Motlagh F, Farasaty F, et al. Factors Related to Personal Protective Equipment Use between Factory Cement Employ in Ilam, the west of Iran: Application of BASNEF Model. J Sci Today's World. 2014;3(2):56-9.

28. Saffari M, Shojaeizadeh D, Ghofranipour F, Heydarnia A, Pakpoir HA Health Education \& Promotion-Theories, Models \& Methods. new edition ed. Tehran: Sobhan Publication; 2012. p. 30.

29. Sharifirad GR, Golshiri P, Shahnazi H, Barati M, Hasanzadeh A, Charkazi A, et al. The impact of educational program based on BASNEF model on breastfeeding behavior of pregnant mothers in Arak [In Persian]. Arak Med Univ J. 2010;13(1):63-70.

30. Hazavehei SMM, Asadi Z, Hassanzadeh A, Shekarchizadeh P. Comparing the effect of two methods of presenting physical education $\Pi$ course on the attitudes and practices of female Students towards regular physical activity in Isfahan University of Medical Sciences [In Persian]. Iran J Med Educ. 2008;8(1):121-31.

31. Arzani A, Mohammadkhan Kermanshahi S, Pasha Zahed YA. Role of discharge planning for mothers on growth and developmental indicators in LBW newborns [In Persian]. J Babol Univ Med Sci. 2005;7(4):58-63.

32. Keramat A, Masoumi SZ, Shobeiri F, Raei M, Andarzgoo M, Babazadeh $R$. Effectiveness of educational program related to persuade women for breast feeding based on theory of planned behavior (TPB) [In Persian]. Sci Journal Hamadan Nurs Midwifery Facul. 2013;21(2):21-31.

33. Baker EJ, Sanei LC, Franklin N. Early initiation of and exclusive breastfeeding in large-scale community-based programmes in Bo- livia and Madagascar.J Health Popul Nutr. 2006;24(4):530-9. [PubMed: 17591350].

34. Gunnarsdottir I, Schack-Nielsen L, Michaelsen KF, Sorensen TI, Thorsdottir I, NordNet Study G. Infant weight gain, duration of exclusive breast-feeding and childhood BMI - two similar follow-up cohorts. Public Health Nutr. 2010;13(2):201-7. doi: 10.1017/S1368980009005874. [PubMed: 19607745].

35. Aidam BA, Perez-Escamilla R, Lartey A. Lactation counseling increases exclusive breast-feeding rates in Ghana. J Nutr. 2005;135(7):1691-5 [PubMed: 15987851].

36. Britton C, McCormick FM, Renfrew MJ, Wade A, King SE. Support for breastfeeding mothers. Cochrane Database Syst Rev. 2007(1):CD001141. doi: 10.1002/14651858.CD001141.pub3. [PubMed: 17253455].

37. Dennis CL, Hodnett E, Gallop R, Chalmers B. The effect of peer support on breast-feeding duration among primiparous women: a randomized controlled trial. CMAJ. 2002;166(1):21-8. [PubMed: 11800243].

38. Finch C, Daniel EL. Breastfeeding education program with incentives increases exclusive breastfeeding among urban WIC participants. Am Diet Assoc. 2002;102(7):981-4. doi:10.1016/S0002-8223(02)90224-5. [PubMed: 12146564].

39. Haider R, Ashworth A, Kabir I, Huttly SR. Effect of communitybased peer counsellors on exclusive breastfeeding practices in Dhaka Bangladesh: a randomised controlled trial [see commments]. Lancet 2000;356(9242):1643-7. doi: 10.1016/S0140-6736(00)03159-7. [PubMed 11089824].

40. Haque MF, Hussain M, Sarkar A, Hoque MM, Ara FA, Sultana S Breast-feeding counselling and its effect on the prevalence of exclusive breast-feeding. J Health Popul Nutr. 2002;20(4):312-6. [PubMed: 12659411].

41. Porteous R, Kaufman K, Rush J. The effect of individualized professional support on duration of breastfeeding: a randomized controlled trial. I Hum Lact. 2000;16(4):303-8. doi: 10.1177/089033440001600406. [PubMed: 11155608].

42. Taveras EM, Li R, Grummer-Strawn L, Richardson M, Marshall R, Rego $\mathrm{VH}$, et al. Opinions and practices of clinicians associated with continuation of exclusive breastfeeding. Pediatrics. 2004;113(4):e283-90. doi: 10.1542/peds.113.4.e283. [PubMed: 15060254].

43. Khoury AJ, Moazzem SW, Jarjoura CM, Carothers C, Hinton A. Breastfeeding initiation in low-income women: Role of attitudes, support, and perceived control. Womens Health Issues. 2005;15(2):64-72. doi 10.1016/j.whi.2004.09.003. [PubMed:15767196].

44. Scott JA, Binns CW, Oddy WH, Graham KI. Predictors of breastfeeding duration: evidence from a cohort study. Pediatrics. 2006;117(4):e64655. doi: 10.1542/peds.2005-1991. [PubMed:16585281].

45. Taveras EM, Li R, Grummer-Strawn L, Richardson M, Marshall R, Rego $\mathrm{VH}$, et al. Mothers' and clinicians' perspectives on breastfeeding counseling during routine preventive visits. Pediatrics. 2004;113(5):e40511. [PubMed: 15121981].

46. Kordi M, Bakhshi M, Tara F, Mokhber N, Ebrahim Zade S. The effect of midwife's supportive care during labor on exclusive breastfeeding in primipara women [In Persian].J Birjand Univ Med Sci. 2010;17(2):79-86.

47. Brown A, Raynor P, Lee M. Young mothers who choose to breast feed the importance of being part of a supportive breast-feeding community. Midwifery. 2011;27(1):53-9. doi: 10.1016/j.midw.2009.09.004. [PubMed: 19896254]

48. Bertini G, Perugi S, Dani C, Pezzati M, Tronchin M, Rubaltelli FF. Maternal education and the incidence and duration of breast feeding: a prospective study. J Pediatr Gastroenterol Nutr. 2003;37(4):447-52. doi: 10.1097/00005176-200310000-00009. [PubMed: 14508215].

49. Morrow AL, Guerrero ML, Shults J, Calva JJ, Lutter C, Bravo J, et al. Efficacy of home-based peer counselling to promote exclusive breastfeeding: a randomised controlled trial. Lancet. 1999;353(9160):122631. doi: 10.1016/S0140-6736(98)08037-4. [PubMed: 10217083].

50. Stewart-Knox B, Gardiner K, Wright M. What is the problem with breast-feeding? A qualitative analysis of infant feeding perceptions.J 
Hum Nutr Diet. 2003;16(4):265-73. [PubMed: 12859708].

51. Shakespeare J, Blake F, Garcia J. Breast-feeding difficulties experienced by women taking part in a qualitative interview study of postnatal depression. Midwifery. 2004;20(3):251-60. doi: 10.1016/j.midw.2003.12.011. [PubMed: 15337281]. 